\title{
The burden of anxiety among people living with HIV during the COVID-19 pandemic in Pune, India
}

Ivan Marbaniang ${ }^{1,2^{*}}$ (D), Shashikala Sangle ${ }^{3}$, Smita Nimkar ${ }^{1}$, Kanta Zarekar $^{1}$, Sonali Salvi ${ }^{3}$, Amol Chavan ${ }^{1}$, Amita Gupta ${ }^{1,4}$, Nishi Suryavanshi ${ }^{1}$ and Vidya Mave ${ }^{1,4}$

\begin{abstract}
Introduction: Globally, India has the third largest population of people living with HIV (PLHIV) and the second highest number of COVID-19 cases. Anxiety is associated with antiretroviral therapy (ART) nonadherence. It is crucial to understand the burden of anxiety and its sources among Asian Indian PLHIV during the COVID pandemic, but data are limited.

Methods: During the first month of government mandated lockdown, we administered an anxiety assessment via telephone among PLHIV registered for care at a publicly funded antiretroviral therapy (ART) center in Pune, India. Generalized anxiety was defined as GAD-7 score $\geq 10$. Sociodemographic and clinical variables were compared by anxiety status (GAD-7 score $\geq 10$ vs GAD-7 score $<10$ ). Qualitative responses to an open-ended question about causes of concern were evaluated using thematic analysis.

Results: Among 167 PLHIV, median age was 44 years (IQR 40-50); the majority were cisgender women (60\%) and had a monthly family income $<200$ USD (81\%). Prior history of tuberculosis and other comorbidities were observed in 38 and 27\%, respectively. Overall, prevalence of generalized anxiety was 25\% $(n=41)$. PLHIV with GAD-7 score $\geq$ 10 had fewer remaining doses of ART than those with lower GAD-7 scores $(p=0.05)$. Thematic analysis indicated that concerns were both health related and unrelated, and stated temporally. Present concerns were often also projected as future concerns.

Conclusions: The burden of anxiety was high during COVID lockdown in our population of socioeconomically disadvantaged PLHIV in Pune and appeared to be influenced by concerns about ART availability. The burden of anxiety among PLHIV will likely increase with the worsening pandemic in India, as sources of anxiety are expected to persist. We recommend the regular use of short screening tools for anxiety to monitor and triage patients as an extension of current HIV services.
\end{abstract}

Keywords: India, COVID-19 pandemic, Poverty, GAD-7, Anxiety, Screening

\footnotetext{
*Correspondence: ivan.marbaniang@mail.mcgill.ca; ivanmarb@gmail.com

${ }^{1}$ Byramjee Jeejeebhoy Government Medical College - Johns Hopkins

University Clinical Research Site, Jai Prakash Narayan Road, Maharashtra

411001 Pune, India

2Department of Epidemiology, McGill University, Purvis Hall, 1020 Pine

Avenue, Montreal, QC H3G 1A2, Canada

Full list of author information is available at the end of the article
}

C The Author(s). 2020 Open Access This article is licensed under a Creative Commons Attribution 4.0 International License, which permits use, sharing, adaptation, distribution and reproduction in any medium or format, as long as you give appropriate credit to the original author(s) and the source, provide a link to the Creative Commons licence, and indicate if changes were made. The images or other third party material in this article are included in the article's Creative Commons licence, unless indicated otherwise in a credit line to the material. If material is not included in the article's Creative Commons licence and your intended use is not permitted by statutory regulation or exceeds the permitted use, you will need to obtain permission directly from the copyright holder. To view a copy of this licence, visit http://creativecommons.org/licenses/by/4.0/. The Creative Commons Public Domain Dedication waiver (http://creativecommons.org/publicdomain/zero/1.0/) applies to the data made available in this article, unless otherwise stated in a credit line to the data. 


\section{Introduction}

The global COVID-19 pandemic and the subsequent lockdowns authorized by governments as containment measures have had a profound impact on mental health. Studies from diverse settings have consistently reported an increase in the burden of mental health conditions during this period [1-3]. The differential power structures that shape social hierarchies are likely instrumental in making certain groups, such as people living with HIV (PLHIV), at higher risk of developing more serious mental health issues [4]. PLHIV already have a disproportionately higher burden of mental health conditions [5], yet the impact of the pandemic is presently not wellunderstood in this potentially vulnerable population.

From a public health standpoint, it is important to understand the relationship between mental health among PLHIV, HIV treatment outcomes and HIV transmission dynamics. Depression is associated with treatment failure $[6,7]$, lower CD4 counts and risky sexual behavior $[8,9]$, and anxiety is associated with disengagement from care $[10,11]$. The importance of generating mental health data among PLHIV in the setting of the pandemic can be inferred given that worsening mental health has been reported in the general population.

Globally, India has the third largest population of PLHIV [12] and had the second highest number of confirmed COVID-19 cases as of September 24, 2020 [13]. A recent meta-analysis of studies from India identified anxiety or depression as risk factors for nonadherence to antiretroviral therapy (ART) [14]. Another meta-analysis that included data from India found that anxiety was associated with $70 \%$ higher odds of ART nonadherence [15]. India's HIV response already functions within an overburdened system [16]. Declining mental health during the pandemic could have a crippling effect on a healthcare system that has been further paralyzed by the rapidly increasing number of COVID-19 cases [17] following the easement of lockdown restrictions on June 8, 2020 [18].

Taking into consideration the findings of the two aforementioned recent meta-analyses; assuming that in a crisis like the COVID-19 pandemic, anxiety precedes depression; and recognizing that the two conditions frequently coexist [19], we sought to quantify the prevalence of anxiety symptoms, and the sources of anxiety among PLHIV in Pune, India.

\section{Methods}

\section{Study population and procedures}

Between April 21, 2020 and May 28, 2020, we recruited a subset of adults ( $\geq 18$ years) enrolled in an ongoing 48month prospective cohort study who needed to reschedule their 4-year study visit due to the government mandated lockdown. The parent study seeks to understand the development of non-communicable diseases among PLHIV; the details have been reported elsewhere [20]. Briefly, participants $(n=400)$ were registered for care at the ART center affiliated with Byramjee Jeejeebhoy Government Medical College and Sassoon General Hospitals (BJGMC-SGH), a publicly-funded tertiary healthcare center in Pune, Maharashtra. The ART center functions under India's National AIDS Control Organization (NACO) and currently provides care to approximately 5000 PLHIV from lower and lowermiddle socioeconomic backgrounds. Pune has consistently reported high HIV prevalence compared to the national average $(0.67 \%$ versus $0.31 \%)$ [21, 22], and Maharashtra is the state most affected by the pandemic, contributing approximately one third of all confirmed COVID-19 cases in India [23].

\section{Ethics}

Two parent study counselors contacted potential participants via telephone $(n=323)$ to reschedule their study visit and also obtained verbal consent for the present study in Marathi, the locally spoken language. Participants had previously consented to being contacted on the phone number used. The Ethics Committee of BJGMC-SGH and Johns Hopkins University approved this project.

\section{Procedures}

Sociodemographic and clinical data were obtained from the parent study. Updated information on marital status, employment, income, CD4 counts and viral loads were obtained from contacted participants. All consenting participants completed: 1) a single General Anxiety Disorder-7 (GAD-7) assessment (available online free of charge) [24], which uses a series of 7 questions to assess anxiety symptoms over the previous 2 weeks; 2) a COVID-19 symptom screen based on the US Centers for Disease Control (CDC) checklist [25]; 3) and history of exposure to COVID-19; and 4) an open-ended question, which was added after the first 38 participants were recruited, "In the present situation, what is/are the most important thing(s) that you are worried about?" Responses to the open-ended question were recorded and translated verbatim from Marathi into English by a translator proficient in both languages.

\section{Outcomes}

Primary outcomes were generalized anxiety disorder at a single timepoint and causes for concern, as reported in response to the open-ended question. Generalized anxiety disorder was defined as GAD-7 score $\geq 10$, which has been shown to have $89 \%$ sensitivity and $82 \%$ specificity [26, 27]; no generalized anxiety disorder was defined as GAD-7 score $<10$. 


\section{Statistical and qualitative analysis}

Sociodemographic and clinical characteristics were compared among participants with and without generalized anxiety disorder (GAD score $\geq 10$ vs. GAD score $<10$ ). Wilcoxon rank sum and Fisher's exact tests were used to evaluate differences in continuous and categorical variables, respectively. As sensitivity analyses, additional GAD-7 score cutoffs $(5,8$ and 15) were used to define generalized anxiety disorder. A two-tailed $p$-value of 0.05 was used to infer statistical significance. All analyses were performed using Stata version 16.0.

Qualitative responses to the open-ended question were examined using thematic analysis. Two authors (IM and $\mathrm{SN}$ ) independently coded these data using an inductive approach. Codes and themes were identified directly from the responses. The results we present are situated within a broadly essentialist framework where the material and experiential reality of participants was taken at face value [28]. Codes and themes were organized in NVivo 12.

\section{Results}

\section{Study population}

Of 323 potential participants, 167 (52\%) were able to be contacted, and all were included in the quantitative analysis. Among those not able to be contacted after three attempts on two separate days $(n=156), 36 \%$ chose not to receive phone calls, $33 \%$ were out of cellular coverage area, and $25 \%$ had provided a phone number that was no longer in use. Overall $(n=167)$, median age was 44 years (IQR 40-50), 60\% were cisgender women $(n=100), 81 \%$ had a monthly household income below 200 USD, and 57\% had been employed in the informal sector prior to the lockdown. A significant proportion were not aware of their latest CD4 counts (40\%) or viral loads (43\%), $38 \%$ had a history of tuberculosis, $27 \%(n=45)$ were living with another comorbid illness, and two participants reported exposure to symptomatic SARS-CoV-2 individuals, but none of the participants reported positive symptomatology (Table 1).

Thematic analysis was conducted on a subset of 122 participant responses, after excluding the first 38 participants (for whom the open-ended question had not been asked) and an additional 7 participants who declined to answer the question.

\section{Prevalence of anxiety}

The GAD-7 scale had high internal consistency among our study population (Cronbach's alpha 0.96). Overall, approximately $25 \%$ of participants $(n=41 / 167)$ reported anxiety symptoms consistent with generalized anxiety disorder. Participants with GAD-7 scores $\geq 10$ were more likely to have fewer remaining days of ART medications $(p=0.05)$ compared to those with scores below 10, and this difference remained significant when the GAD-7 cutoff was raised to $15(p=0.02)$. Other variables did not differ significantly by GAD-7 score, even when alternative cutoffs were applied. When stratified by gender, cisgender men with GAD-7 scores $\geq 10$ were more likely to be living without a spouse and marginally more likely to have a monthly family income below 130 USD $(p=0.09)$ than those with scores below 10; among cisgender women, GAD-7 scores were independent of living with a spouse (supplementary file). These gender-specific findings were no longer significant when the GAD-7 cut-off was changed to 5,8 or 15 , indicating that significance was a function of the cut-off used and hence unreliable.

\section{Causes of anxiety}

The following four themes were identified in thematic analysis: a) concerns related to the immediate present; b) concerns related to the imminent future; c) lack of social and financial support; and d) indifference to circumstances secondary to COVID-19; themes a) and b) were further classified as health-related or health-unrelated. Cognizant of the qualitative framework of thematic analysis, we do not quantify the exact number of participants who expressed each theme. However, two-thirds expressed themes A and B, roughly one half expressed theme $\mathrm{C}$, and one third expressed theme $\mathrm{D}$.

\section{Theme a: concerns associated with the immediate present} Immediate health-related concerns were articulated as perceived increased susceptibility to COVID-19 or beliefs of being infected with COVID-19 in the absence of symptoms. These appeared to directly stem from participants' self-awareness of immunodeficiency due to HIV.

"I have low CD4 counts and I am also taking medicines for tuberculosis. I am scared that I will get infected with coronavirus." (cisgender man, GAD-7 score: 2 )

"I have low immunity because of HIV, I am worried of getting COVID-19 infection. I feel that even a common cold could be coronavirus." (cisgender woman, GAD-7 score: 10)

Immediate non health-related concerns centered around financial insecurity resulting from unemployment and a lack of savings and predominantly drove apprehensions about food security, eviction, and the ability to provide for the family.

"I am a construction worker. I am at home with my two children. My wife is dead. Currently I am worried about how the house will run as there is no 
Table 1 Distribution of GAD-7 scores of by sociodemographic and clinical characteristics among PLHIV contacted

\begin{tabular}{|c|c|c|c|c|}
\hline & $\begin{array}{l}\text { Total } \\
\text { N (\%) }\end{array}$ & $\begin{array}{l}\text { GAD-7 } \geq 10 \\
\text { n (\%) }\end{array}$ & $\begin{array}{l}\text { GAD-7 < } 10 \\
\text { n (\%) }\end{array}$ & $p$-value \\
\hline $\mathrm{N}(\%)$ & 167 & $41(24.6)$ & $126(75.4)$ & - \\
\hline Median age in years (IQR) & $44(40-50)$ & $43(40-49)$ & $45(40-50)$ & 0.8 \\
\hline \multicolumn{5}{|l|}{ Gender } \\
\hline Cisgender men & $66(39.5)$ & $17(41.5)$ & $49(38.9)$ & \multirow[t]{3}{*}{0.3} \\
\hline Cisgender women & $100(59.9)$ & $23(56.1)$ & $77(61.1)$ & \\
\hline Transgender woman & $1(0.6)$ & $1(2.4)$ & 0 & \\
\hline \multicolumn{5}{|l|}{ Monthly household income (USD) } \\
\hline$<65$ & $35(20.9)$ & $11(26.8)$ & $24(19.0)$ & \multirow[t]{4}{*}{0.6} \\
\hline $65-130$ & $64(38.3)$ & $14(34.1)$ & $50(39.6)$ & \\
\hline $131-199$ & $36(21.6)$ & $10(24.4)$ & $26(20.6)$ & \\
\hline$\geq 200$ & $32(19.2)$ & $6(14.6)$ & $26(20.6)$ & \\
\hline \multicolumn{5}{|l|}{ Education } \\
\hline No formal education & $22(13.2)$ & $4(9.8)$ & $18(14.3)$ & \multirow[t]{3}{*}{0.4} \\
\hline$\leq 9$ years & $74(44.3)$ & $22(53.7)$ & $52(41.3)$ & \\
\hline$>9$ years & $71(42.5)$ & $15(36.6)$ & $56(44.4)$ & \\
\hline \multicolumn{5}{|l|}{ Employment prior to lockdown ${ }^{a}$} \\
\hline Unemployed & $33(19.8)$ & $9(21.9)$ & $24(19.0)$ & \multirow[t]{3}{*}{0.5} \\
\hline Informal sector & $95(56.9)$ & $25(61.0)$ & $70(55.6)$ & \\
\hline Salaried & $39(23.3)$ & $7(17.1)$ & $32(25.4)$ & \\
\hline \multicolumn{5}{|l|}{ Living with a spouse } \\
\hline Yes & $83(49.7)$ & $19(46.3)$ & $64(50.8)$ & \multirow[t]{2}{*}{0.7} \\
\hline No & $84(50.3)$ & $22(53.7)$ & $62(49.2)$ & \\
\hline Median duration on ART in years (IQR) & $9.8(6.5-12.9)$ & $9.5(6.7-11.8)$ & $9.9(6.4-13.1)$ & 0.4 \\
\hline \multicolumn{5}{|l|}{ Latest CD4 counts (cells/mm³) } \\
\hline$<500$ & $44(26.4)$ & $10(24.4)$ & $34(26.9)$ & \multirow[t]{3}{*}{0.8} \\
\hline$\geq 500$ & $57(34.1)$ & $13(31.7)$ & $44(34.9)$ & \\
\hline Do not know & $66(39.5)$ & $18(43.9)$ & $48(38.1)$ & \\
\hline \multicolumn{5}{|l|}{ Latest viral load } \\
\hline Undetectable (<50 copies $/ \mathrm{mL})$ & $87(52.1)$ & $16(39.0)$ & $71(56.3)$ & \multirow[t]{3}{*}{0.1} \\
\hline$\geq 50$ copies $/ \mathrm{mL}$ & $9(5.4)$ & $3(7.3)$ & $6(4.8)$ & \\
\hline Do not know & $71(42.5)$ & $22(53.7)$ & $49(38.9)$ & \\
\hline \multicolumn{5}{|l|}{ Prior history of tuberculosis } \\
\hline Yes & $64(38.3)$ & $19(46.3)$ & $45(35.7)$ & \multirow[t]{2}{*}{0.3} \\
\hline No & $103(61.7)$ & $22(53.7)$ & $81(64.3)$ & \\
\hline \multicolumn{5}{|l|}{ Living with another comorbidity ${ }^{b}$} \\
\hline Yes & $45(27.0)$ & $12(29.3)$ & $33(26.2)$ & \multirow[t]{2}{*}{0.7} \\
\hline No & $122(73.0)$ & $29(70.7)$ & $93(73.8)$ & \\
\hline Median days of remaining ART (IQR) & $60(28-76)$ & $32(17-60)$ & $60(30-79)$ & 0.05 \\
\hline Discontinued ART during the lockdown & $5(3.3)$ & - & - & - \\
\hline
\end{tabular}

ART Antiretroviral Therapy

Median GAD-7 score for the study population was 3 (IQR: 0-9), range 0-21

${ }^{a}$ Informal sector employment for women mainly included working as house maids or domestic help (89\%), for men this was mainly as daily wage laborers (92\%)

${ }^{b}$ Comorbidity includes having any of the following: COPD, asthma, CVD, hypertension, diabetes, renal disease, cancer 
money and no work." (cisgender man, GAD-7 score:12)

"As the only earning member of my family, I am worried. My children are young. We are doing whatever it takes to get by, but because of the lockdown I am unemployed now. The house is rented. I cannot return to my village either." (cisgender man, GAD-7 score: 6)

"There is no food at home currently and I cannot feed my children. I am a housewife and I have no income or savings. The children used to earn by washing cars." (cisgender woman, GAD-7 score: 10)

\section{Theme B: concerns associated with the imminent future}

Imminent health-related concerns were articulated as apprehension about COVID-19 persistence continuing to endanger personal health following a reopening.

"I work as a care counsellor in the ART center. There are no coronavirus patients at this time point, but I am worried what will happen if they visit the center in the future?" (cisgender man, GAD-7 score: 1)

"I am scared to return to get my medicines at the ART center after the lockdown, if coronavirus does not end. Coronavirus must end." (cisgender woman, GAD-7 score: 5 )

Imminent non health-related concerns included fears about shortages of opportunities for gainful employment or dismissal from current employment and fed into anxieties about an uncertain future that such eventualities would ensue. Such fears often co-existed with an anticipation for "normality".

"I am a sex worker. My business is closed and I have no clients because of the lockdown. I will die of hunger if the virus continues. I am worried all the time. If coronavirus doesn't end, then what?" (cisgender woman, GAD-7 score: 5)

"I am going to lose my job because of this lockdown. I am eager to know when will COVID-19 end, when will we go back to normal life?" (cisgender woman, GAD-7 score: 9)

"I stay with my mother and sold fruits for a living. Now that has closed, and I don't know when I will be able to start again. When will COVID-19 end? When can we start normal life?" (cisgender woman, GAD-7 score: 12 )
Theme C: lack of social and financial support

Isolation from family members and friends accompanied feelings of loneliness and helplessness, and the lack of financial buffers perpetuated these feelings.

"I stay alone. I used to run a beauty salon that I rented, which is now closed. I have no money to pay the owner who is asking for rent. I have no savings and no one to talk to. I have a lot of tension and I feel lonely." (cisgender woman, GAD-7 score: 21)

"I stay alone. My daughter is recently married. I worked in a company, but it has closed. I have no salary and I stay in a rented house. I receive no help from my in-laws who stay in the same neighborhood." (cisgender woman, GAD-7 score: 10)

This theme was also common among migrant workers from outside or within the state.

"My family is in Bihar (a state 900 miles to the east). I want to go home, but I can't. There is a lot of tension and I worry a lot. I have no work and no money now." (cisgender male, GAD-7 score: 21 )

\section{Theme $D$ : indifference to circumstances secondary to COVID-19}

Some remained unperturbed by the pandemic and its control measures. However, this indifference appeared to be closely linked to a sense of security by virtue of a profession, continuing employment or location.

"I work in the fields. There is no coronavirus there. Everything is fine." (cisgender man, GAD-7 score: 0)

"Now, I have work on the sewing machine, and I am not worried at all." (cisgender woman, GAD-7 score: 0 )

"I do not get out of the house and I am not worried at all." (cisgender woman, GAD-7 score: 0 )

\section{Discussion}

This survey found high prevalence of generalized anxiety disorder (GAD-7 score $\geq 10$ ) among PLHIV during the lockdown due to COVID-19 in Pune, India. More severe anxiety was not differentially distributed by age, gender, or socioeconomic background, underscoring the pervasiveness of anxiety symptoms in the current pandemic. Additionally, a range of health-related and health unrelated factors directly linked to the pandemic, affected participants' perceptions, and shaped their present beliefs and future expectations. Anxiety symptoms 
pervasive in the current pandemic, have implications for HIV outcomes.

One study from Hong Kong conducted during the early phases of the pandemic used the GAD-7 scale and found marginally lower prevalence of anxiety among HIV uninfected individuals with age and gender distributions comparable to our study population [29]. However, the largest study to report on anxiety symptoms among Asian Indian PLHIV found notably higher prevalence than our study [30]. We primarily attribute this incongruency to different scales and classifications used among these studies, but acknowledge that perceptions of diminished vulnerability to COVID-19 among some individuals, as evidenced in our qualitative findings, could also play a role. It is, therefore, imperative that our results not be interpreted in isolation, but rather in the context of the evolving pandemic in India.

As mentioned earlier, nonadherence to ART is one of many adverse effects of anxiety [14, 15]. While our study population is appreciably small, potential nonadherence among 25\% could have far reaching consequences for viral suppression, HIV transmission and antiviral resistance in the community [31]. Because mental health services are not integrated within the Indian HIV-care delivery framework [32], linkage to mental health providers falls outside the realm of HIV-programmatic capabilities. Further, such linkages are not always feasible given India's severe shortage of trained mental health professionals [33]. With mental health conditions on the rise during the current pandemic [34], linkage to care becomes even more challenging. Since anxiety, the deficiency of mental health services and ART nonadherence are interdependent [11], it is not difficult to surmise the negative effect that the pandemic could have on India's 90-90-90 goals. Notably, we intend to follow up with participants who had GAD-7 scores $\geq 10$ and repeat the assessment after 2 months. In the event of a persistently high GAD-7 score, we will link that individual to a mental health professional at BJGMCSGH.

We identified three themes that broadly encapsulate the causes for concern reported across a wide range of GAD-7 scores. As exhibited by participants remarks, one theme could be a predominant cause of concern, but more often than not, themes were interconnected. Thus, a present cause of concern could also be a recurring future concern. It is not untenable to extrapolate from the participants' statements that the chronicity of a particular concern directly depends on how quickly the concern (financial, social or apprehensions about personal health) is addressed. We have represented this as a conceptual framework in
Fig. 1. Although the themes we identified may not seem specific to PLHIV, they must first be contextualized to our participants' existing socioeconomic backgrounds and the manner in which the pandemic will potentially affect their vertical social mobility. Secondly, the themes need to be understood from the perspective of low socioeconomic status and restricted social mobility and how these will affect HIV treatment outcomes.

More than $50 \%$ of our participants earn less than the 2019-2020 estimated monthly per-capita income for India [35], completed less than 10 years of education, and were either employed in the informal sector or were unemployed prior to the lockdown. The Indian government has responded to the financial crisis among the poor with two programs, namely the Pradhan Mantri Garib Kalyan Yojana (PMGKY) and the second tranche of the Atmanirbhar Bharat [36]. These stimulus programs have been criticized as providing a lower level of support than those offered by other governments [36, 37]. Analysis also indicates that instead of mobilizing additional funding, PMGKY has reallocated funding across existing budgets or allowed individuals to make advance withdrawals, raising concerns about the long-term utility of these measures for the poor [36, 38]. Furthermore, the World Bank estimates that the COVID-19 pandemic could push a substantial section of individuals with socioeconomic status similar to our study population into extreme poverty [39]. The association between socioeconomic deprivation and poor mental health is well-established [40]. Worsening mental health is foreseeable for most of our study population and would impact HIVtreatment outcomes (through reduced adherence, increased antiviral resistance, etc.) among a group of disadvantaged individuals within an already vulnerable population.

Interestingly, while none of the participants directly expressed concern about the remaining doses of ART, we found that patients with fewer remaining doses had significantly higher GAD-7 scores compared to those with more doses. This suggests that although concern about ART availability may not be at the forefront, it could be affecting anxiety levels among PLHIV. Notably, a recent survey conducted by the World Health Organization (WHO) showed several countries to be at risk for stock outs of ART [41]. However, the deputy director general of NACO has assured that India will not face such a crisis [42]. This is encouraging news for Asian Indian PLHIV, which will likely go a long way to allaying underlying fears. Indian policy makers need to consider whether access to ART during this pandemic is as uncompromised as the ART stocks. 


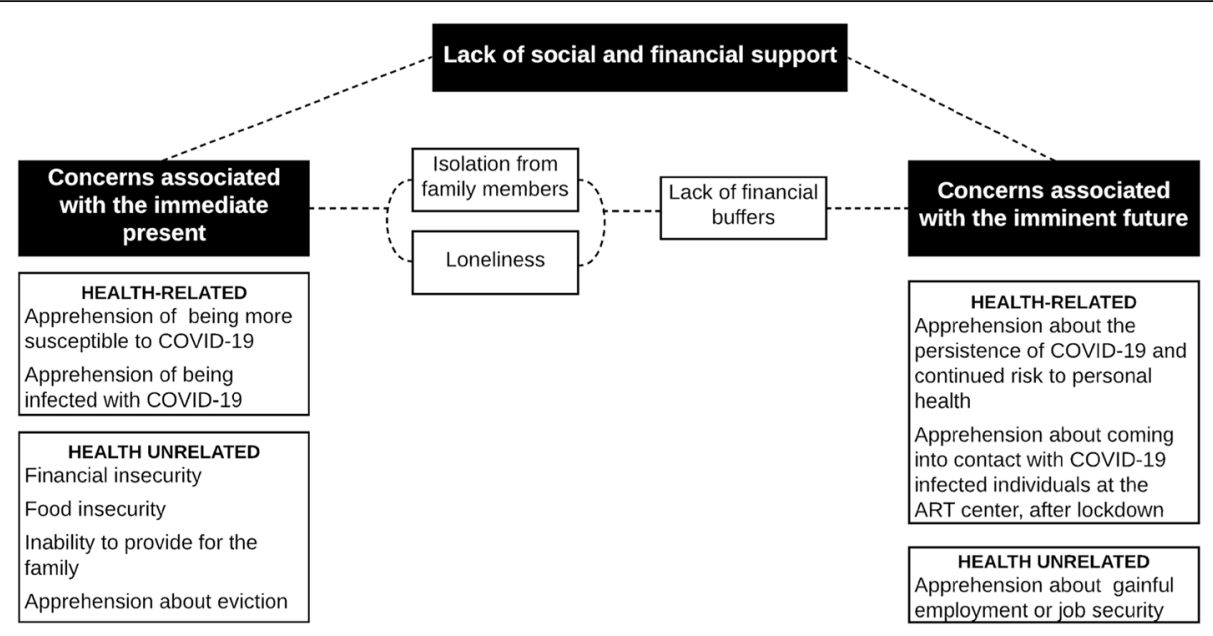

Fig. 1 Three themes (black boxes) were identified in thematic analysis as causes of concern. As indicated by dotted lines, the themes were not always mutually exclusive. However, one theme could be a predominant cause of concern. Causes of concern also appeared to recur and their persisience implicated in the absence of mitigating measures. As an example, participants were concerned in the immediate present about not having any money to be able to provide for the family. In the absence of financial buffers such as savings, this concern was also projected into the imminent future

There are a few limitations to our findings. First, due to the small sample size, our results cannot be extrapolated to all PLHIV in Pune. However, because the socioeconomic backgrounds of patients registered for care at the ART center are largely homogenous, the reported prevalence of anxiety symptoms and consequences of these anxiety levels could be generalizable to them. Second, as we do not have GAD-7 scores prior to the lockdown, we cannot conclude with absolute certainty that the present levels observed are entirely attributable to the pandemic. However, participant concerns were almost exclusively related to the pandemic, the GAD-7 assessed anxiety over the two preceding weeks, and our study was carried out 1 month into the lockdown in India. Therefore, we largely ascribe the observed anxiety levels to the pandemic. It is also difficult to determine whether we have underestimated or overestimated the prevalence of anxiety symptoms, even within our cohort, especially given the high non-response rate. While it may seem likely that patients with higher levels of anxiety would be more apt to refuse our calls, it is equally plausible that responders were more anxious. In addition, the thematic analysis was conducted on responses to a single question, which limits a more nuanced understanding of the issue at hand. However, using thematic analysis as a guiding framework allowed us to more concretely consolidate the wealth of information provided by our participants into definitive themes. Lastly, although we did not observe differences in GAD7 scores by comorbidity or prior tuberculosis status, we are unable to comment on how mental health in such individuals will change over time given their higher risk for COVID-19 infection [43, 44] and what that will mean in terms of disengagement from care or HIV treatment outcomes for PLHIV with these conditions. We are instituting longitudinal follow-up of all study participants and will better understand these associations by the end of 2020.

\section{Conclusion}

Despite our limitations, our findings provide important insights into the burden and sources of anxiety symptoms in a small group of Asian Indian PLHIV. To our knowledge, these findings are the first to be reported among PLHIV from India during the current pandemic. Our findings also come with the sobering implication that the COVID-19 pandemic will have devastating effects on the mental health of Asian Indian PLHIV as well as downstream HIV-related treatment outcomes, especially as the pandemic continues to grow in India and particularly for PLHIV who are socioeconomically disenfranchised. Sweeping financial assistance along with extensive social and health support mechanisms would indeed be a panacea for COVID-related anxiety symptoms among PLHIV, but are impracticable. Instead, we recommend that HIV care providers regularly use readily available, short screening tools to identify and prioritize PLHIV at risk for anxiety and other mental health conditions. This strategy will not redress the deleterious effects of the pandemic on HIV care but might at least reduce their impact. 


\section{Supplementary information}

Supplementary information accompanies this paper at https://doi.org/10. 1186/s12889-020-09656-8.

Additional file 1. Crosstabulation between GAD-7 scores and income when stratified by gender. Crosstabulation between GAD-7 scores and living with a spouse when stratified by gender.

\section{Abbreviations}

PLHIV: People living with HIV; ART: Antiretroviral therapy; BJGMC -

SGH: Byramjee jeejeebhoy government medical college and sassoon general hospitals; NACO: National AIDS control organization; GAD-7: General anxiety disorder-7; PMGKY: Pradhan mantri garib kalyan yojana

\section{Acknowledgements}

The authors express their gratitude to all the participants who took time to respond to our telephone calls and provide us with the wealth of information they have, in this time of crisis. We would also like to thank Rohini Kamble who helped with data entry and Suhasini Surwase who helped collect some of the data that was used for this analysis. Lastly, we would like to acknowledge Katherine McIntire for her contributions with scientific language editing.

\section{Authors' contributions}

IM conceived the idea, conducted the thematic analysis and authored the first draft. ShS and SoS provided intellectual input and helped to contextualize the analytical findings to the existing health program. SN conducted the study on the ground and coded for thematic analysis. KZ collected all the data that was used. AC cleaned the data and performed statistical analysis. AG, NS provided inputs to the manuscript and helped with its final form. VM provided technical expertise and helped with manuscript drafting. All authors reviewed the manuscript and provided inputs. The author(s) read and approved the final manuscript.

\section{Funding}

The author(s) disclosed receipt of the following financial support for the research, authorship, and/or publication of this article: This study was supported through a grant from amfAR, The Foundation for AIDS Research with support from the National Institute of Health's National Institute of Allergy and Infectious Diseases, Eunice Kennedy Shriver National Institute of Child Health and Human Development, National Cancer Institute, National Institute of Mental Health, National Institute on Drug Abuse, the National Heart, Lung, and Blood Institute, the National Institute on Alcohol Abuse and Alcoholism, the National Institute of Diabetes and Digestive and Kidney Diseases, and the Fogarty International Centre, as part of the International Epidemiology Databases to Evaluate AIDS (leDEA; U01Al069907) and the $\mathrm{NIH}$-funded Johns Hopkins Baltimore-Washington-India Clinical Trials Unit for NIAID Networks [UM1AI069465]. The content and views expressed are those of the authors and does not necessarily represent the official views of any of the governments or institutions mentioned above.

\section{Availability of data and materials}

The datasets used and/or analyzed during the current study are available from the corresponding author on reasonable request.

\section{Ethics approval and consent to participate}

The BJGMC- SGH and Johns Hopkins University Ethics Committees approved this study, and all study participants provided verbal consent that are in accordance with the Indian Council of Medical Research (ICMR) guidelines.

\section{Consent for publication}

Not applicable as no individual data has been used.

\section{Competing interests}

The authors declare that they have no competing interests.

\section{Author details}

${ }^{1}$ Byramjee Jeejeebhoy Government Medical College - Johns Hopkins University Clinical Research Site, Jai Prakash Narayan Road, Maharashtra 411001 Pune, India. ${ }^{2}$ Department of Epidemiology, McGill University, Purvis
Hall, 1020 Pine Avenue, Montreal, QC H3G 1A2, Canada. ${ }^{3}$ Department of General Medicine, Byramjee Jeejeebhoy Government Medical College, Pune, Maharashtra, India. ${ }^{4}$ Department of Medicine and Infectious Diseases, Johns Hopkins University, Baltimore, MD, USA.

Received: 19 July 2020 Accepted: 7 October 2020

Published online: 23 October 2020

\section{References}

1. Mazza C, Ricci E, Biondi S, Colasanti M, Ferracuti S, Napoli C, et al. A nationwide survey of psychological distress among Italian people during the covid-19 pandemic: immediate psychological responses and associated factors. Int J Environ Res Public Health. 2020;17(9):3165.

2. González-Sanguino C, Ausín B, Castellanos M, Saiz J, López-Gómez A, Ugidos C, Muñoz M. Mental health consequences during the initial stage of the 2020 Coronavirus pandemic (COVID-19) in Spain. Brain Behav Immun. 2020;87:172-6.

3. Li J, Yang Z, Qiu H, Wang Y, Jian L, Ji J, et al. Anxiety and depression among general population in China at the peak of the COVID-19 epidemic. World Psychiatry. 2020;19(2):249-50.

4. Holmes EA, O'Connor RC, Perry VH, Tracey I, Wessely S, Arseneault L, et al. Multidisciplinary research priorities for the COVID-19 pandemic: a call for action for mental health science. Lancet Psychiatry. 2020;7(6):547-60.

5. Remien RH, Stirratt MJ, Nguyen N, Robbins RN, Pala AN, Mellins CA. Mental health and HIV/AIDS: the need for an integrated response. AIDS. 2019;33(9): 1411-20.

6. Krumme AA, Kaigamba F, Binagwaho A, Murray MB, Rich ML, Franke MF. Depression, adherence and attrition from care in HIV infected adults receiving antiretroviral therapy. J Epidemiol Commun Health. 2015;69(3): 284-9.

7. Marconi VC, Wu B, Hampton J, Ordonez CE, Johnson BA, Singh D, et al. Early warning indicators for first-line virologic failure independent of adherence measures in a south African urban clinic. AIDS Patient Care STDs. 2013; 27(12):657-68

8. Alemu H, Mariam DH, Tsui A, Ahmed S, Shewamare A. Effect of depressive symptoms and social support on weight and CD4 count increase at HIV clinic in Ethiopia. AIDS Care. 2012;24(7):866-76.

9. Wagner GJ, Ghosh-Dastidar B, Holloway IW, Kityo C, Mugyenyi P. Depression in the pathway of HIV antiretroviral effects on sexual risk behavior among patients in Uganda. AIDS Behav. 2012;16(7):1862-9.

10. Gonzalez A, Solomon SE, Zvolensky MJ, Miller CT. The interaction of mindful-based attention and awareness and disengagement coping with HIV/AIDS-related stigma in regard to concurrent anxiety and depressive symptoms among adults with HIV/AIDS. J Health Psychol. 2009;14(3):403-13.

11. Rooks-Peck CR, Adegbite AH, Wichser ME, Ramshaw R, Mullins MM, Higa D, et al. Mental health and retention in HIV care: a systematic review and meta-analysis. Health Psychol. 2018;37(6):574-8.

12. National AIDS Control Organization (NACO). India HIV Estimations 2017: Technical Report 2017

13. Dong $E$, Du H, Gardner L. An interactive web-based dashboard to track COVID-19 in real time. Lancet Infect Dis 2020, 20(5):533-534; COVID-19 Dashboard by the Centre for Systems Science and Engineering (CSSE) at Johns Hopkins University: Johns Hopkins University; 2020. Retrieved September 30, 2020, from: https://coronavirus.jhu.edu/map.html.

14. Chakraborty A, Hershow RC, Qato DM, Stayner L, Dworkin MS. Adherence to antiretroviral therapy among HIV patients in India: a systematic review and meta-analysis. AIDS Behav. 2020;24(7):2130-48.

15. Wykowski J, Kemp CG, Velloza J, Rao D, Drain PK. Associations between anxiety and adherence to antiretroviral medications in low- and middleincome countries: a systematic review and meta-analysis. AIDS Behav. 2019; 23(8):2059-71.

16. Gopalan HS, Misra A. COVID-19 pandemic and challenges for socioeconomic issues, healthcare and National Health Programs in India. Diabetes Metab Syndr Clin Res Rev. 2020;14(5):757-9.

17. Rukmini S. How covid-19 response disrupted health services in rural India livemint 2020 [Available from: https://www.livemint.com/news/india/howcovid-19-response-disrupted-health-services-in-rural-india-11587713155817. html.

18. Schultz K, Sameer Y. "Its Coronavirus Caseload Soaring, India Is Reopening Anyway." The New York Times. 2020. Last modified July 12, 2020.https:// 
www.nytimes.com/2020/05/29/world/asia/coronavirus-india-lockdown.html. Accessed $15 \mathrm{Jul} 2020$.

19. Saddock BJ, Saddock VA, Ruiz P. Kaplan \& Sadock's comprehensive textbook of psychiatry. In., vol. I, Tenth edition. edn. [Philadelphia]: Wolters Kluwer; 2017:1731-5.

20. Marbaniang I, Sangle S, Salvi S, Kulkarni V, Shere D, Deshpande P, et al. High prevalence of insulin resistance and occurrence prior to hyperinsulinemia threshold among people living with HIV in Pune, India. Diabetes Metab Syndr. 2019;13(3):1813-9.

21. Joshi RK, Mehendale SM. Determinants of consistently high HIV prevalence in Indian districts: a multi-level analysis. PLoS One. 2019;14(5):e0216321.

22. Maharashtra State AIDS Control Society (2018-2019). "HIV Sentinel Surveillance." Retrieved July 10, 2020, from https://mahasacs.org/index. php?option=com_content\&view=article\&id=39\&ltemid=59\&lang=en

23. Covid-19 state tally: Maharashtra closer to 3 lakh-mark; 12 states have more than 20,000 cases hindustan times 2020 [Available from: https://www. hindustantimes.com/india-news/covid-19-state-tally-maharashtra-closer-to-3lakh-mark-12-states-have-more-than-20-000-cases/story-5TnleOk23 rOGeyMkCOnnkJ.html.

24. Spitzer, R. L., J. B. W. Williams and K. Kroenke "GAD-7 Marathi for India (Pfizer )." Retrieved July 15, 2020, from https://www.phqscreeners.com/ images/sites/g/files/g10060481/f/201412/GAD7_Marathi\%20for\%20India. pdf.

25. National Center for Immunization and Repiratory Diseases (NCIRD), Division of Viral Diseases, CDC. (2020, May 13, 2020). "Coronavirus Disease 2019 (COVID-19) : Symptoms of Coronavirus." Retrieved July 20, 2020, from https://www.cdc.gov/coronavirus/2019-ncov/symptoms-testing/symptoms. html.

26. Rutter LA, Brown TA. Psychometric properties of the generalized anxiety disorder Scale-7 (GAD-7) in outpatients with anxiety and mood disorders. Psychopathol Behav Assess. 2017;39(1):140-6.

27. Spitzer RL, Kroenke K, Williams JB, Löwe B. A brief measure for assessing generalized anxiety disorder: the GAD-7. Arch Intern Med. 2006;166(10): 1092-7.

28. Braun V, Clarke V. Using thematic analysis in psychology. Qual Res Psychol. 2006:3(2):77-101.

29. Choi EPH, Hui BPH, Wan EYF. Depression and anxiety in Hong Kong during COVID-19. Int J Environ Res Public Health. 2020;17(10):3740.

30. Joshi B, Chauhan S, Pasi A, Kulkarni R, Sunil N, Bachani D, et al. Level of suboptimal adherence to first line antiretroviral treatment \& its determinants among HIV positive people in India. Indian J Med Res. 2014; 140(1):84-95.

31. Cohen MS, Chen YQ, McCauley M, et al. Prevention of HIV-1 infection with early antiretroviral therapy. N Engl J Med. 2011;365(6):493-505.

32. National AIDS Control Programme Care Support and Treatment Services: National AIDS Control Organization; October 2018 [Available from: https:// Ims.naco.gov.in/frontend/content/NACO\%20-\%20National\%20Technical\%2 OGuidelines\%20on\%20ART_October\%202018\%20(1).pdf.

33. Bagcchi S. Rethinking India's psychiatric care. Lancet Psychiatry. 2014;1(7): 503-4.

34. Naik A. "As India's Lockdown Ends, a Mental Health Crisis Is Just Beginning." World Economic Forum. 2020. Last modified 18 May 2020.https://www. weforum.org/agenda/2020/05/indias-lockdown-ends-mental-health-crisisbeginning/. Accessed 5 June 2020.

35. Press Trust of India. (2020, January 7, 2020). "India's per-capita income rises 6.8\% to Rs 11,254 a month in FY20." Retrieved June 30, 2020, from https:// www.businesstoday.in/current/economy-politics/india-per-capita-incomerises-68-to-rs-11254-a-month-in-fy20/story/393333.html.

36. Bharali I, Kumar P, Selvaraj S, Mao W, Ogbuoji O, Hille H, Yamey G. India's policy response to COVID-19. The Center for Policy Impact in Global Health. Policy Report: June 2020 Available at: http://centerforpolicyimpact.org/ourwork/the-4ds/indias-policy-response-to-covid-19/.

37. Detrixhe, John (2020, March 17, 2020). "Government bailouts are beginning: We're keeping track (QUARTZ)." Retrieved Jul 6, 2020, from https://qz.com/1 819776/here-are-the-coronavirus-bailouts-being-prepared-around-theworld/.

38. Khaitan NJ Utsav H Gagwani, Shreya. India's COVID19 financial package: rehashed existing Programmes, Little New Spending Available from: https:// www.indiaspend.com/indias-covid19-financial-package-rehashed-existingprogrammes-little-new-spending/.
39. Sanchez-Paramo C. "Covid-19 Will Hit the Poor Hardest. Here's What We Can Do About It." World Bank Blogs. 2020. Last modified April 23, 2020 https://blogs.worldbank.org/voices/covid-19-will-hit-poor-hardest-hereswhat-we-can-do-about-it. Accessed 18 June 2020.

40. Ng E, Muntaner C, Chung H, Eaton WW. The Wiley Blackwell encyclopedia of health, illness, behavior, and society: chapter: socioeconomic status and mental illness. Chichester, West Sussex, UK: Wiley Blackwell; 2014.

41. World Health Organization. "WHO: Access to HIV Medicines Severely Impacted by Covid-19 as AIDS Response Stalls (News Release)." WorldHealth Organization. Last modified July 6, 2020. https://www.who.int/news-room/ detail/06-07-2020-who-access-to-hiv-medicines-severely-impacted-bycovid-19-as-aids-response-stalls. Accessed 15 July 2020.

42. Mascarenhas A. "India Won't Face Stock-Outs of Antiretroviral Medicine as Result of COVID-19: NACO." The Indian Express. Last modified July 7, 2020. https://indianexpress.com/article/india/india-wont-face-stock-outs-ofantiretroviral-medicine-as-result-of-covid-19-naco-6494866/. Accessed 25 July 2020.

43. WHO Team, Global Tuberculosis Programme. "Q\&A: Tuberculosis and Covid19." World Health Organization. Last modified 11 May 2020. https://www. who.int/news-room/q-a-detail/tuberculosis-and-the-covid-19-pandemic. Accessed 4 June 2020.

44. Maragakis L. "Coronavirus and Covid-19: Who Is at Higher Risk?" Johns Hopkins Medicine, copyright The Johns Hopkins University, The JohnsHopkins Hospital, and Johns Hopkins Health System. Last modified June 25, 2020. https://www.hopkinsmedicine.org/health/conditions-anddiseases/coronavirus/coronavirus-and-covid19-who-is-at-higher-risk. Accessed 1 July 2020.

\section{Publisher's Note}

Springer Nature remains neutral with regard to jurisdictional claims in published maps and institutional affiliations.

\section{Ready to submit your research? Choose BMC and benefit from:}

- fast, convenient online submission

- thorough peer review by experienced researchers in your field

- rapid publication on acceptance

- support for research data, including large and complex data types

- gold Open Access which fosters wider collaboration and increased citations

- maximum visibility for your research: over $100 \mathrm{M}$ website views per year

At BMC, research is always in progress.

Learn more biomedcentral.com/submissions 